\title{
An Interactive and Self-instructional Virtual Chemistry Laboratory
}

\author{
$\underline{\text { http://dx.doi.org/10.3991/ijet.v11i07.5853 }}$ \\ Laiali Almazaydeh ${ }^{1}$, Ismael Younes ${ }^{1}$, Khaled Elleithy ${ }^{2}$ \\ ${ }^{1}$ Al-Hussein Bin Talal University, Ma'an, Jordan \\ ${ }^{2}$ University of Bridgeport, Bkridgeport, CT, USA
}

\begin{abstract}
Virtual laboratory is becoming one of the most significant educational technologies due to financial challenges which often required construction of physical laboratories, particularly in educational institutions in developing countries. This paper presents an integrated virtual environment to help individual learners to enhance the practical learning of chemistry fundamentals. Through this environment, the learner will navigate, visualize and simulate a real laboratory environment and its associated processes. The proposed laboratory interface and curriculum were tested on students to measure their satisfaction with the quality of developed laboratory. The results of the evaluation showed a positive response effect on the students' satisfaction.
\end{abstract}

Index Terms - Virtual Chemistry Laboratory, VCL, chemistry, chemical reactions, simulation, virtual environment, Learning.

\section{INTRODUCTION}

There is a major growth in the usage of technology to support learning in the last several years. Virtual laboratory is becoming one of the most remarkable educational technologies in academic and technological development. Virtual laboratory could take place instead of traditional laboratory, where the learners will have the ability to simulate the learning process as more realistic as possible in different science subjects such as chemistry, physics, biology and computer networks [1].

Chemistry is a centric science. It plays a critical role in most aspects of all other natural sciences and it touches different issues in the environment, space sciences, medicine, and more [2]. In chemistry and natural science, the experiential learning and laboratory is essential, and at the same time the most significantly method for understanding related knowledge and retention of material by learners [3]. However, applying some scientific experiments as traditional forms at real laboratory environment have rarely been conducted due to scarcity of economic resources and other insufficient facilities which often required for the construction of complete laboratory, particularly in developing countries [4].

An alternative learning environment could be found in the adaptation of virtual laboratory technology, which will simulate a real laboratory environment and processes [5]. This kind of interactive technology brings many advantages. These advantages include, the possibility of making virtual practical experimentation accessible by students who cannot physically attend the actual laboratory for any reason [6], simulating dangerous experiments that require careful handling of incendiary or toxic chemical materials without riskiness students or others, strengthening students' ability of exploration and independent knowledge, and finally, providing students a high level of continuous lifetime learning, where they might need to repeat the experiment as many times to grasp the concepts well.

This paper examines the development of a Virtual Chemistry Laboratory (VCL) where the learner will navigate, visualize and simulate a real laboratory environment and processes.

The paper is structured as follows: Section II elaborates a variety of related studies in the field of VCL. Section III presents details of the proposed VCL. Section IV is about the experiment and results of our VCL. Finally section V is related with conclusion.

\section{RELATED WORKS}

The development of virtual laboratory has become a high demand technology to support constructing an interactive learning environment that responds to the individual learner's actions and behaviors by means of animation techniques, video, and advanced graphics [7] [8].

Researchers have emphasized that performing practical experimentation within a virtual laboratory significantly enhances the student's academic achievement, fosters motivation towards the course, and provides perception of abstract scientific concepts [5], [9-11].

A virtual industrial chemical laboratory was developed by a department of chemical engineering at Texas Tech University [12]. This system was intended for the use of a double-pipe heat exchanger interface, cooling tower interface and a gas absorber interface that are used by the new chemical engineers in order to learn the safety concerns associated with these equipment in industry [4].

A virtual chemistry laboratory at Charles Sturt University in Australia [13] was designed in order to enable distance education students to get comfortable with the layout of the laboratory building prior to their first residential school. This virtual environment is helpful only for students to train them for identifying and locating items within the real laboratory.

At Brigham young University in the United States, a virtual ChemLab was developed [14]. In virtual ChemLab a set of realistic laboratory simulations for fundamental experiments in chemistry is illustrated as a movie metaphor. The purpose of those simulations is to enhance student understanding of the chemical theory taught in the classroom, and their imaginative learning capabilities.

Model ChemLab is also used for virtual laboratory environment, which was developed by Model Science Software Incorporation Canada [15]. Similarly the Model 


\section{SHORT PAPER \\ AN INTERACTIVE AND SELF-INSTRUCTIONAL VIRTUAL CHEMISTRY LABORATORY}

ChemLab contains a set of laboratory simulation, where every simulation is contained in a different loadable module. The laboratory experiment and its required tools were made through menus option and dialogue boxes [4].

Most of the above related works shows that there is not that much work out there that involves integrated virtual learning environment, meanwhile, from giving the user the interaction ability by setting up the experiment, till test his/her acquired knowledge through e-exam. However, more research is being achieved and the interest is developing.

\section{PROPOSED LABORATORY OVERVIEW}

The principle goal of our research work is the development of a computer-based environment with remarkable capabilities of effective translation of theoretical chemical concepts into visualized actions alongside with the potential of the learners' interaction with them. What's more, to take more enthusiasm for chemistry practical learning, this in real life could be limited due to time, economic and safety factors.

The system architecture has been developed with friendly user interfaces for VCL. In Figure 1, the overall inside scenario of the proposed laboratory is illustrated. The student can access the VCL services provided as shown in that figure after using username and password assigned by an administrator.

The periodic table, calculator, equations balancing, experiments simulation and e-exam are visualized in interactive form inside the laboratory. All the chemical elements are placed in the periodic table where the learner can freely identify them either with preliminary information such as: group number, name, symbol, atomic number and mass number, or with additional detailed information such as: year of discovery, uses, characteristics, electronic distribution and the chemical element associated image in the nature. Figure 2 shows detailed information of Hydrogen.

With the main interface the learner also will be able to select any chemical element to interact with other one, save the chemical reactions, and retrieve the saved chemical interaction. Figure 3 shows all the previous chemical reactions made and saved by the user.

Through main interface interaction the user can choose the calculator unit which provides different calculation such as molarity, molality, number of moles, density, and the percentage, as shown in Figure 4.

Experiments simulation is considered one of the most significant interactive parts in our proposed VCL. Here, our focusing to make the experiment closer to reality.

In Figure 5, the user can easily navigate in the virtual environment to select the required chemicals according to the experiment from the rack and brings it to the experimental table, as other necessary instruments such as teaspoon, glassware, and syringe are placed on the table.

Suppose in a scenario to perform an experiment to show interaction between elements from the first chemicals group on the left hand side, e.g. Na, with an element from the seventh chemicals group on the right hand side, e.g. Cl. First, you should choose one of these elements by one click on it then drag and release on the table and take the other element the same way. Now, the two elements are on the table. Catch the spoon to take some from the

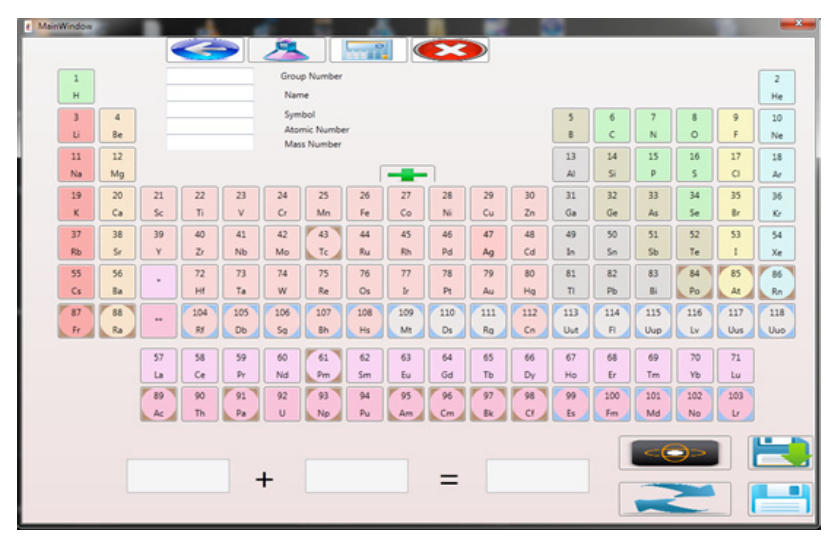

Figure 1. VCL interface

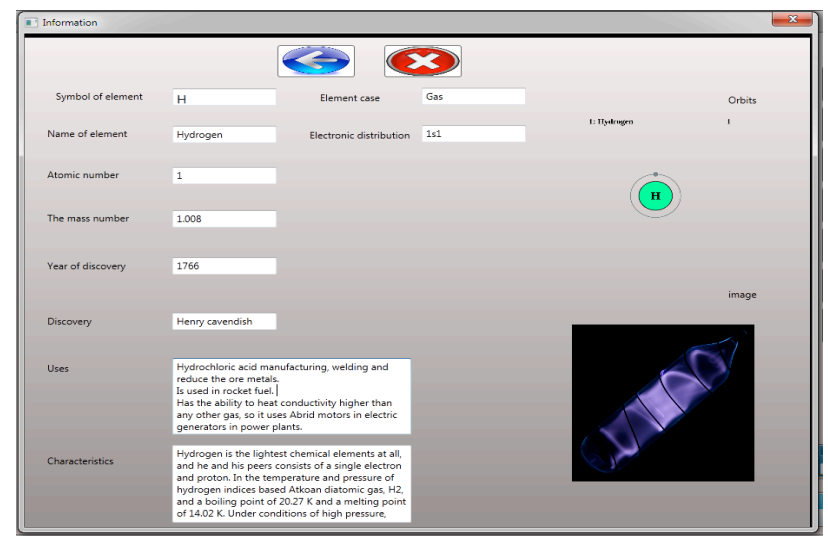

Figure 2. Detailed information of chemical element

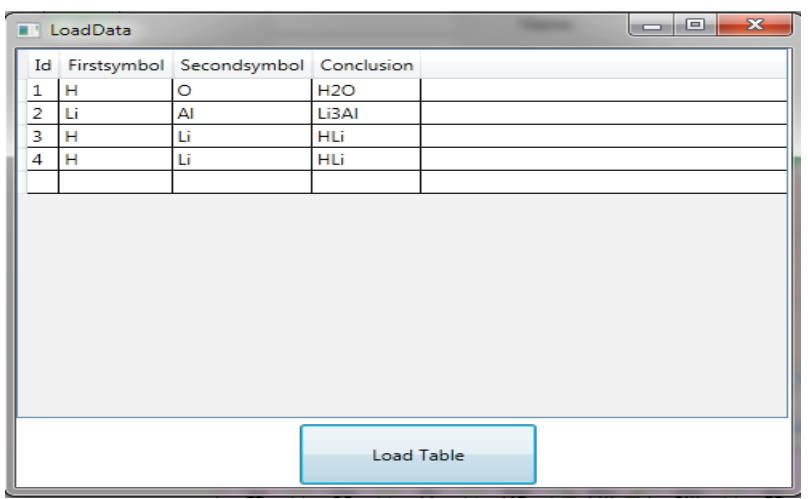

Figure 3. Retraived Chemical reactions

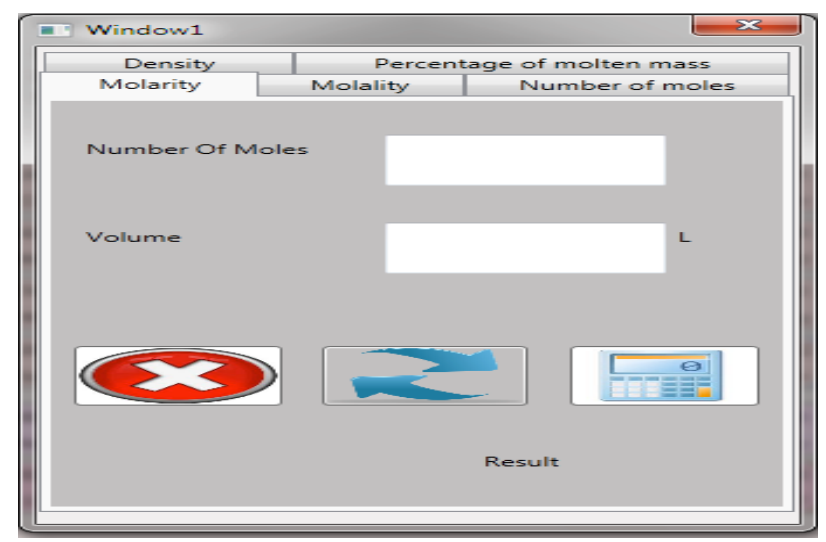

Figure 4. Chemical calculator 


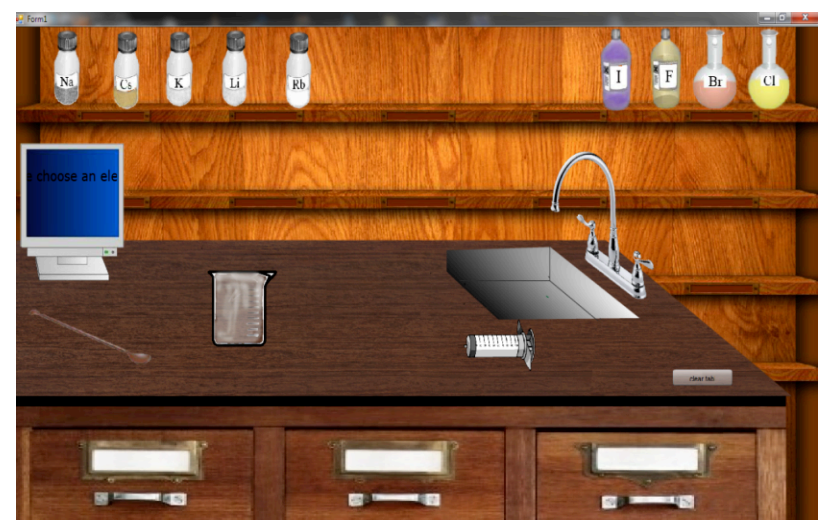

Figure 5. Simulation Environment

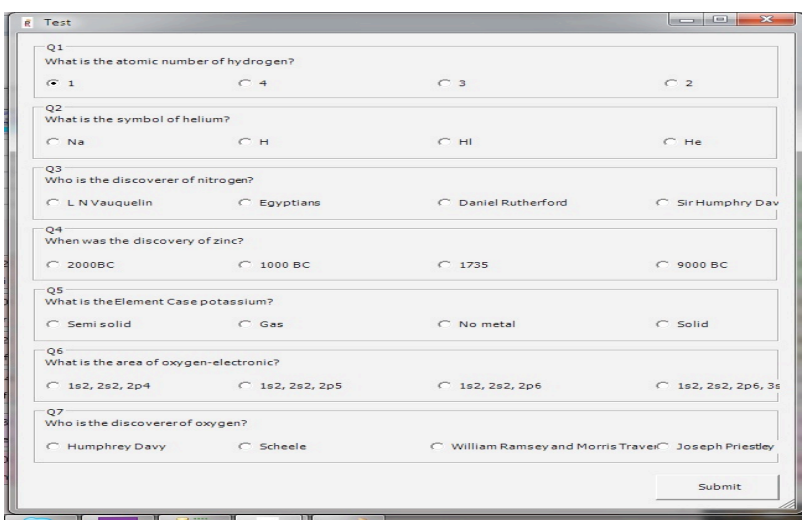

Figure 6. e-exam interface

first element by releasing it on the top of the element battle. Now, the spoon is full of the first element, take the full spoon and drag it to the glassware which you want to make the interaction in, and release the spoon. You will watch the glassware full of the element which you chose. The other element you will choose is from the seventh group which need the syringe to fill the glassware in. The same way you follow to fill the glassware. When the two elements are in the interaction glassware, they will interact together. In the real interaction its effects is light and temperature. This what you will observe in the glassware when you will watch the fire in the glassware.

The VCL also contains a virtual board which displays information about the required steps to simulate the experiment procedure successfully with a textual feedback on virtual board.

The last part of the proposed VCL is e-exam part, as shown in Figure 6. This interface contains a group of questions about chemistry which already exist on the VCL. The questions are multiple choice questions, where the user could evaluate his/her related knowledge.

\section{EXPERIMENTS AND EVALUATION}

The complete VCL environment is implemented in visual C\#, WPF using C\#, Flash CS6 and SQL server.

We performed the experiments by 25 participants divided into two samples. The first sample consisted of 15 high school students' respondents, and the second sample consisted of 10 undergraduate students. The participants were asked to interact with the VCL as they assume the level of realism in the virtual learning environment. Through interaction the participant manipulates the VCL to perform different tasks. The participants easily navigated the VCL objects. They identified the chemical elements, performed different calculations, balanced different equations, simulated the virtual experiments, and tested their related knowledge. However, even that the VCL contains embedded tutorial video and help instructional menu, the participants find that there is no need for preliminary demonstration.

After simulating the VCL each participant asked to evaluate his/her experimental results by a questionnaire especially designed for this purpose. This questionnaire aims at gauging the user's satisfaction with the VCL and evaluating the used virtual environment in general. The advantages of the questionnaire that it is quick and can be analyzed more rigorously.

The questionnaire had been divided into two main parts. The first part is the general information such as education level and age. The second part is questions with scaled answers to test and evaluate the VCL.

As shown in Table I, $60 \%$ of the respondents were high school students and 40\% were undergraduate students.

In this questionnaire, scale had been set as follows:

$1=$ Strongly disagree, $2=$ Disagree, $3=$ Neutral, 4=Agree, $5=$ Strongly agree

Table II shows the Mean for the two main evaluation criteria which related to match between the system and the real world and ease of use.

TABLE I.

GENERAL DATA SUMMARY

\begin{tabular}{|c|c|c|}
\hline Age & Frequency & Percentage (\%) \\
\hline $16-18$ & 15 & 60 \\
\hline $19-21$ & 10 & 40 \\
\hline
\end{tabular}

TABLE II.

DESCRIPTIVE STATISTICS

\begin{tabular}{|c|c|c|}
\hline Dimension & Number & Mean \\
\hline $\begin{array}{c}\text { Match between the system and the } \\
\text { real world }\end{array}$ & 6 & 3.91 \\
\hline Ease of use & 3 & 4.07 \\
\hline
\end{tabular}

The following are some of the descriptive questions that we have asked the participants to evaluate the VCL:

1. The main idea of the virtual environment is clear and understandable.

2. The main windows of the virtual environment are consistent and very structured.

3. The project matches between the system and the real world.

4. Using VCL would enable me to accomplish tasks more quickly.

5. The VCL has aesthetic and minimalist design.

6. The available help manual is helpful.

7. I would find VCL to be flexible to interact with.

8. It would be easy for me to become skillful at using VCL.

9. I would find VCL easy to use.

As shown in Table II the descriptive statistics for all items are with a mean higher than 4 which indicates that all of the participants agreed on using the VCL. 


\section{AN INTERACTIVE AND SELF-INSTRUCTIONAL VIRTUAL CHEMISTRY LABORATORY}

\section{CONCLUSION}

In this paper we presented a virtual learning environment for chemistry fundamentals course, which facilitates real laboratory work, due to instruments limitation or other reasons. The overall evaluation proves positive response from each participant by using the proposed VCL.

\section{REFERENCES}

[1] A. Alexiou, C. Bouras and E. Giannaka, "VIRTUAL LABORATORIES IN EDUCATION, A cheap way for schools to obtain laboratories for all courses, by using the Computer Laboratory", Springer, IFIP TC3 Technology Enhanced Learning Workshop (Tel'04), World Computer Congress, August 22-27, 2004, Toulouse, France, pp. 19-28

[2] David Yaron, et. al, "Virtual Laboratories and Scenes to Support Chemistry Instruction:Lessons Learned", Web-enabled Learning Environments, pp. 177-182.

[3] N. Herga, D. Dinevski,"Virtual Laboratory in Chemistry - Experimental Study of Understanding, Reproduction and Application of Acquired Knowledge of Subject's Chemical Content", Organizacija, Vol. 45, No. 3, May-June 2012, pp.108-116.

[4] N. Ali, S. Ullah, A. Alam, and J. Rafique, "3D Interactive Virtual Chemistry Laboratory for Simulation of High School Experiments", pp. 1-5.

[5] Z. Tatli and A. Ayas, "Effect of a Virtual Chemistry Laboratory on Students' Achievement”, Technology \& Society, vol. 16, no.1, pp.159-170.

[6] A. Nassar, M. Mohammed, A. Elrashidi, K. Elleithy, " Virtual Wireless and Mobile Communication Laboratory", Education 2012, vol. 2, no. 1, pp. 19-24. http://dx.doi.org/10.5923/j.edu. 20120201.04

[7] H. Babateen, "The role of Virtual Laboratories in Science Education", $20115^{\text {th }}$ International Conference on Distance Learning and Education.

[8] D. Shin, E. Yoon, K. Lee, E. Lee, “A web-based, interactive virtual laboratory system for unit operations and process systems engineering education: issues, design and implementation", Com- puters and Chemical Engineering 26 (2002), Elsevier , pp. 319330.

[9] J. A. Al-Sharhan. "Teaching Aids and the Recent of Education Technology", Al-Himadi printers, Riyadh, 2005.

[10] Z. Lal, and A. Al-Gindi, "Electronic Communication and Education Technology", T3, Al-Obaikan, Riyadh. 2005.

[11] A. Martinez, " Learning in chemistry with virtual laboratories", Journal of Chemical Education, 2003, vol. 80, no. 3, pp. 346-352. http://dx.doi.org/10.1021/ed080p346

[12] S. Vaidyanath, J. Williams, M. H. T. W., "The development and deployment of a virtual unit operations laboratory", In Chemical Engineering Education, 2007, pp. 144-152.

[13] B. Dalgarno, A.G. Bishop, and D.R.B. Jr., "The potential of virtual laboratories for distance education science teaching: reflections from the development and evaluation of a virtual chemistry laboratory", UniServe Science Conference proceedings, 2003.

[14] B.F. Woodfield, "The virtual ChemLab project: a realistic and sophisticated simulation of organic synthesis and organic qualitative analysis", Journal of Chemical Education., 82: pp. 17281735, 2005. http://dx.doi.org/10.1021/ed082p1728

[15] Model Science Software. http://modelscience.com/chemedu.html? ref=home\&link=chemed., Accessed 25 January 2014.

\section{AUTHORS}

Laiali Almazaydeh is with the Faculty of Information Technology, Al-Hussein Bin Talal University, Ma'an, Jordan (e-mail: lalmazay@my.bridgeport.edu).

Ismail Younes is with the Faculty of Information Technology, Al-Hussein Bin Talal University, Ma'an, Jordan (e-mail: abu_iead_92@yahoo.com).

Khaled Elleithy is with the Faculty of Computer Science and Engineering, University of Bridgeport, Bridgeport, CT, USA (e-mail: elleithy@bridgeport.edu).

Submitted 16 May 2016. Published as resubmitted by the authors 18 June 2016. 